02

\title{
Флуоресцентные свойства и электронная структура комплексных соединений неодима(III) с карбоновыми кислотами
}

\author{
(С) И.В. Калиновская, Ю.М. Николенко \\ Институт химии Дальневосточного отделения РАН, \\ 690022 Владивосток, Россия \\ e-mail: kalinovskaya@ich.dvo.ru
}

Поступила в редакцию 10.05.2018 г.

\begin{abstract}
Методами люминесцентной и рентгеноэлектронной спектроскопии изучены разнолигандные комплексные соединения неодима(III) с карбоновыми кислотами, азот- и фосфорсодержащими нейтральными лигандами, люминесцирующие в ближней инфракрасной области. Обнаружено, что при координации нейтральных лигандов посредством донорного атома азота наблюдается тенденция к увеличению электронной плотности на ионе неодима(III).
\end{abstract}

DOI: $10.21883 /$ OS.2018.09.46548.121-18

Комплексные разнолигандные соединения неодима(III) с карбоновыми кислотами, имеющие люминесценцию в ближней ИК области, представляют интерес в качестве преобразователей ультрафиолетового излучения в излучение ближнего инфракрасного диапазона. Эта способность комплексных соединений неодима(III) изучалась при решении ряда биомедицинских задач [1-3], использовании люминесцентных меток в иммунофлуоресцентном анализе [4]. Актуально также использование таких преобразователей для увеличения чувствительности кремниевых приемников, собственная чувствительность которых максимальна в ближнем ИК диапазоне [4,5]. Люминесцентные свойства комплексных соединений изучены в основном в растворах [6,7]. Известны работы по исследованию ИК люминесценции иона неодима(III) в комплексах с $\beta$-дикетонами [7-9], порфиринами $[10]$. В качестве $\beta$-дикетонов были использованы длинноцепочечные производные ацетилацетона, содержащие во фторированном радикале остатки перфторэнантовой и перфторпеларгоновой кислот [7]. Полученные нами ранее разнолигандные соединения неодима(III) с карбоновыми кислотами обладают люминесценцией в ближней ИК области [9]. Значительный вклад в изучение деталей электронного строения комплексов вносит метод рентгеноэлектронной спектроскопии (РЭС). Работ по изучению методом РЭС комплексных соединений редкоземельных элементов недостаточно [11-14].

Цель настоящей работы - изучение электронного строения и флуоресцентных характеристик ряда разнолигандных соединений неодима(III) с трифторуксусной, толуиловой (MBA), хинальдиновой (Quin), коричной (Cin) кислотами и нейтральными лигандами - 1,10-фенантролином (phen), дифенилгуанидином (dphg), 2,2-дипиридилом (dipy), трифенилфосфиноксидом (tppo), сопоставление спектрально-люминесцентных характеристик соединений с зарядовым состоянием иона неодима(III).

\section{Экспериментальная часть}

Для синтеза комплексных соединений использовали следующие препараты марки „ч“: шестиводный хлорид неодима(III), карбоновые кислоты, нейтральные лиганды. Синтез разнолигандных комплексных соединений неодима(III) с карбоновыми кислотами осуществлялся по методикам [9]. Синтезированные соединения перекристаллизовывали из этилового спирта. Чистоту полученных соединений контролировали методом химического элементного анализа, рентгенофазового анализа, УФ и ИК спектроскопии. Спектры люминесценции регистрировали на спектрометре СДЛ-1 с фотоумножителем ФЭУ-62 в интервале 840-1100 nm. Люминесценцию возбуждали ксеноновой лампой ДКсШ-130 в интервале 500-600 nm с использованием светофильтров СЗС-23, С3С-26 и ЖС-18. Образцы снимались при комнатной температуре в кюветах из пирекса. Концентрация этанольных растворов комплексных соединений равна $10^{-5} \mathrm{~mol} / \mathrm{l}$.. Спектры поглощения полученных разнолигандных соединений регистрировали на спектрофотометре СФ-256 УВИ.

Рентгеноэлектронные спектры $1 s$-электронов углерода, кислорода, азота и $3 d$-электронов неодима измерены при комнатной температуре на электронном спектрометре ЭС-2401 (ФГУП ЭЗАН, г. Черноголовка, Россия) с использованием $\mathrm{Al} K \alpha$-излучения $(1489.6 \mathrm{eV})$. Вакуум в камере анализатора энергий поддерживался на уровне $6 \cdot 10^{-8} \mathrm{~mm} \mathrm{Hg}$. Шкала энергии прибора была откалибрована с использованием справочных данных для энергии связи $\left(E_{c}\right) \mathrm{Au} 4 f_{7 / 2}$ и $\mathrm{Cu} 2 p_{3 / 2}$, равных 84.0 и $932.7 \mathrm{eV}$ соответственно [15]. Спектры толуилатов, хинальдинатов и циннаматов калибровались по $E_{c}$ $\mathrm{C} 1 s$-электронов бензольных колец толуиловой, хинальдиновой и коричной кислот $(284.9 \mathrm{eV})$ [16]. Точность определения $E_{c}$ составляла $0.1 \mathrm{eV}$. Компьютерная аппроксимация спектров проводилась с помощью свободно распространяемой программы XPSPeak41. 
Таблица 1. Рентгенометрические данные соединений неодима(III) с карбоновыми кислотами, азот- и фосфорсодержащими нейтральными лигандами

\begin{tabular}{c|r|r|c|c|c}
\hline \multicolumn{2}{c|}{$\left[\mathrm{Nd}(\mathrm{Cin})_{3}\right]_{n}$} & \multicolumn{2}{c|}{$\left[\mathrm{Nd}(\mathrm{MBA})_{3} 2 \mathrm{phen}\right]_{2}$} & \multicolumn{2}{c}{$\left[\mathrm{Eu}(\mathrm{MBA})_{3} 2 \mathrm{dipy}\right]_{2}$} \\
\hline$d, \AA$ & $I / I_{0}$ & $d, \AA$ & $d, \AA$ & $I / I_{0}$ & $I / I_{0}$ \\
\hline 11.35 & 100.0 & 12.10 & 9.87 & 10.0 & 60.0 \\
6.57 & 29.2 & 11.59 & 7.88 & 15.62 & 31.2 \\
5.62 & 25.0 & 10.10 & 7.43 & 25.65 & 100.0 \\
4.47 & 24.4 & 9.57 & 6.73 & 20.55 & 34.4 \\
4.26 & 22.5 & 8.81 & 5.80 & 100.00 & 11.3 \\
3.69 & 10.0 & 6.29 & 5.51 & 40.11 & 16.0 \\
3.46 & 10.4 & 5.59 & 5.28 & 30.60 & 11.0 \\
2.95 & 9.1 & 4.78 & 4.68 & 10.60 & 11.1 \\
2.28 & 9.5 & 4.23 & 4.56 & 10.00 & 12.0 \\
2.11 & 9.5 & 3.90 & 4.19 & 40.00 & 10.3 \\
1.97 & 9.9 & 3.54 & 4.06 & 30.00 & 11.3 \\
1.81 & 10.9 & 3.45 & 3.85 & 20.00 & 11.2 \\
& & & 3.51 & 25.00 & 11.2
\end{tabular}

\section{Результаты и их обсуждение}

Рентгенографическое исследование синтезированных разнолигандных комплексных соединений неодима(III), выполненное по методу порошка, подтвердило их индивидуальность (табл. 1). Фазовый анализ свидетельствует об отсутствии рефлексов исходных веществ и возможных примесей. Полученные комплексные соединения неодима(III) устойчивы на воздухе.

В работе [9] нами подробно были изучены спектры поглощения полученных комплексных разнолигандных соединений неодима(III) с изучаемыми карбоновыми кислотами. Было установлено, что максимум поглощения сдвинут в более длинноволновую область в случае комплексных соединений неодима(III) с м-толуиловой кислотой $(320 \mathrm{~nm})$. Наибольшая интенсивность поглощения характерна для комплексных соединений неодима(III) с коричной кислотой.

На рис. 1 представлены спектры флуоресценции кристаллических разнолигандных соединений неодима(III) с коричной, м-толуиловой, хинальдиновой кислотами и нейтральными лигандами. Люминесценцию комплексных соединений в кристаллическом состоянии снимали при комнатной температуре. $4 f$-люминесценция синтезированных соединений неодима(III) наблюдается в области $850-1100 \mathrm{~nm}$ (ближняя ИК область) с максимумом при $1060 \mathrm{~nm}$ (при возбуждении в диапазоне 450-600 nm) (рис. 1). Спектры флуоресценции разнолигандных соединений неодима(III) с коричной, толуиловой и хинальдиновой кислотами характеризуются двумя достаточно интенсивными полосами переходов: первая $\lambda_{\max }=903-907 \mathrm{~nm}$ (переход $\left.{ }^{4} F_{3 / 2}-{ }^{4} I_{9 / 2}\right)$ и вторая $\lambda_{\max }=1060-1065 \mathrm{~nm}$ (переход ${ }^{4} F_{3 / 2}-{ }^{4} I_{11 / 2}$ ). Наиболее интенсивным в полученных спектрах флуоресценции являются полосы ${ }^{4} F_{3 / 2}-{ }^{4} I_{11 / 2}$-перехода, состоящего из 1-2 интенсивных полос.

Методом РЭС нами впервые изучено электронное строение ряда синтезированных разнолигандных карбоксилатов неодима(III) с азот- и фосфорсодержащими нейтральными лигандами. Полученные данные позволили изучить изменение зарядового состояния центрального иона неодима(III) в группах комплексных карбоксилатов неодима(III). Характерный для всего ряда исследованных комплексных соединений экспериментальный спектр $\mathrm{Nd} 3 d$ образца $\left[\mathrm{Nd}(\mathrm{MBA})_{3}-\text {-bipy }\right]_{2}$ представлен на рис. 2. Помимо компонент $3 d_{5 / 2}$ и $3 d_{3 / 2}$ спинорбитального дублета основного состояния $3 d^{9} 4 f^{3}$ в спектре наблюдаются сигналы, обусловленные немоно-

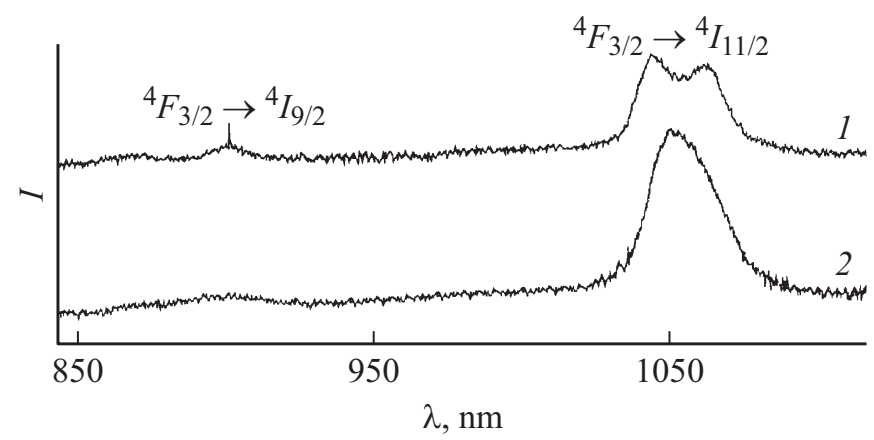

Рис. 1. Спектры люминесценции (77 К) соединений неодима(III): $1-\left[\mathrm{Nd}(\mathrm{Cin})_{3}\right]_{n} ; 2-\left[\mathrm{Nd}(\mathrm{MBA})_{3} \cdot \text { bipy }\right]_{2}$.

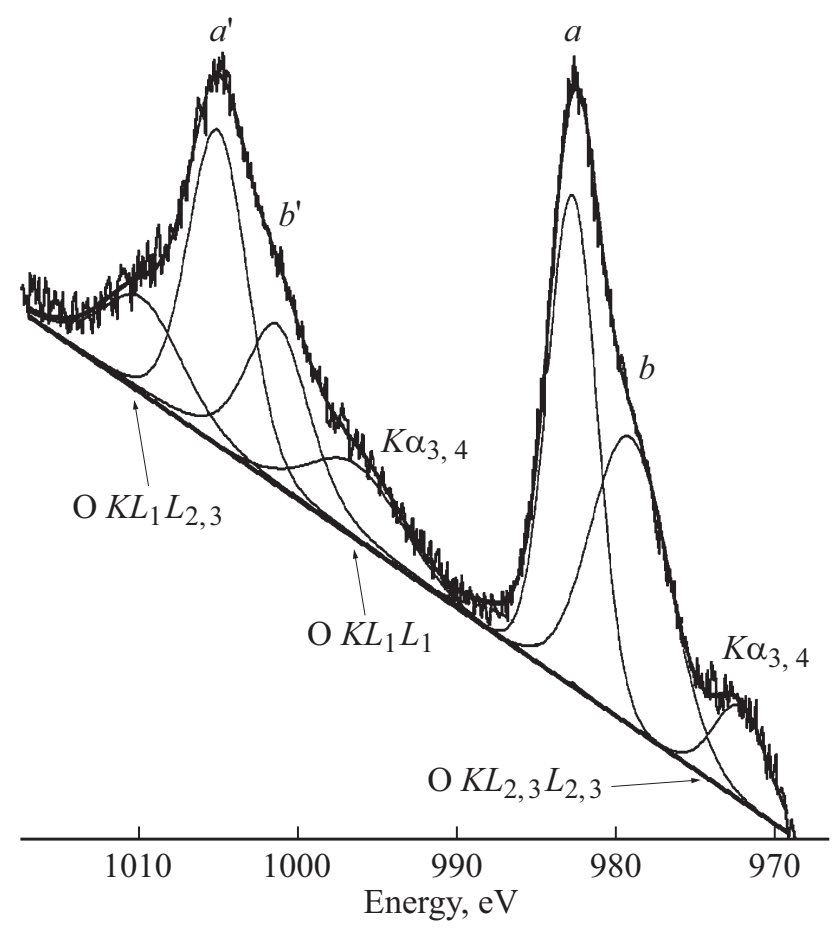

Рис. 2. Рентгеноэлектронные спектры $\mathrm{Nd} 3 d$ соединения $\left[\mathrm{Nd}(\mathrm{MBA})_{3} \cdot \text { bipy }\right]_{2}$ с разделением на компоненты: $a-\mathrm{Nd} 3 d_{5 / 2}$, $b$ - shake-down, $a^{\prime}-\mathrm{Nd} 3 d_{3 / 2}, b^{\prime}-$ shake-down. Интервалы энергий сателлитов $K \alpha_{3,4}$ и некоторых компонент ожеспектра О $K L L$ совпадают. 
Таблица 2. Относительная интенсивность ${ }^{4} F_{3 / 2}-{ }^{4} I_{11 / 2}$-перехода и энергии связи $(\mathrm{eV}) \mathrm{C} 1 s-$, O $1 s-$, $\mathrm{N} 1 s-$ и $\mathrm{Nd} 3 d$-электронов соединений неодима(III) с карбоновыми кислотами, азот- и фосфорсодержащими нейтральными лигандами

\begin{tabular}{|c|c|c|c|c|c|}
\hline Соединение & $\mathrm{C} 1 s$ & $\mathrm{O} 1 s$ & $\mathrm{~N} 1 s$ & $\mathrm{Nd} 3 d$ & $I_{\text {rel }}{ }^{4} F_{3 / 2}-{ }^{4} I_{11 / 2}, \%$ \\
\hline$\left[\mathrm{Nd}(\mathrm{MBA})_{4}\right]_{2} \cdot 2 \mathrm{dphg}$ & $\begin{array}{l}284.9 \\
289.0 \\
291.6\end{array}$ & 532.3 & 400.0 & $\begin{array}{c}983.4 \\
983.4 \\
1005.8\end{array}$ & 19.2 \\
\hline$\left[\mathrm{Nd}(\mathrm{MBA})_{3} \cdot \text { bipy }\right]_{2}$ & $\begin{array}{l}284.9 \\
288.6\end{array}$ & 532.0 & 399.5 & $\begin{array}{c}982.9 \\
1005.3\end{array}$ & 52.0 \\
\hline$\left[\mathrm{Nd}(\mathrm{Cin})_{3}\right]_{n}$ & $\begin{array}{l}284.9 \\
288.9 \\
291.8\end{array}$ & 531.8 & & $\begin{array}{c}983.2 \\
1005.6\end{array}$ & 70.0 \\
\hline $\mathrm{Nd}(\mathrm{Cin})_{3} \cdot 2$ phen $\cdot \mathrm{H}_{2} \mathrm{O}$ & $\begin{array}{l}284.9 \\
288.7\end{array}$ & 531.5 & 399.2 & $\begin{array}{c}982.4 \\
1004.7\end{array}$ & 77.0 \\
\hline$\left[\mathrm{Nd}(\text { Quin })_{3}\right]_{n}$ & $\begin{array}{l}284.9 \\
286.0 \\
288.8\end{array}$ & 532.1 & 399.5 & $\begin{array}{c}983.0 \\
1005.3\end{array}$ & 19.0 \\
\hline $\mathrm{Nd}(\text { Quin })_{3} \cdot$ tppo & $\begin{array}{l}284.9 \\
288.7\end{array}$ & 531.7 & 399.3 & $\begin{array}{c}982.7 \\
1005.2\end{array}$ & 17.0 \\
\hline
\end{tabular}

хроматичностью источника рентгеновского излучения (присутствие в спектре возбуждающего излучения компоненты $\left.\mathrm{Cu} K \alpha_{3,4}\right)$. Соответствующие интервалы энергии обозначены „K$\alpha_{3,4}$ “ (рис. 2). Также на энергетический спектр $3 d$-электронов неодима накладываются эмиссионные $K L L$ оже-линии кислорода [17] карбоксильных групп лигандов (рис. 2). Кроме этого, регистрируются сигналы сателлитов shake-down. Присутствие последних характерно для некоторых редкоземельных металлов и связанно с особенностями экранирования остовных дырок, возникающих в процессе фотоионизации Изначально незанятое локализованное состояние на $4 f$-уровне при образовании остовной дырки становится ниже по энергии, чем другие нелокализованные валентные состояния с меньшим угловым моментом $(5 d, 6 s)$. Оно может быть заполнено переносом делокализованного электрона лиганда с реализацией конечного состояния $3 d^{9} 4 f^{4} \quad[18,19,20]$. В итоге экранирование остовной дырки улучшается, и выбитый фотоэлектрон покидает образец с большей кинетической энергией. При этом в спектре регистрируются сателлитные линии с $E_{\text {св }}$ меньшими, чем $E_{\mathrm{cв}}$ основных компонент $\mathrm{Nd} 3 d$ спинорбитального дублета (рис. 2).

В табл. 2 приведены значения $E_{\mathrm{cB}} 1 s$-электронов углерода, кислорода, азота пиридинового кольца и $3 d$-электронов неодима(III). В однотипных рядах (при координации центрального иона донорным атомом азота нейтральных лигандов) $E_{\text {св }} \mathrm{Nd} 3 d$ уменьшается, свидетельствуя о допировании электронной плотности с нейтральных лигандов на ион неодима(III) (табл. 2). Этот эффект наиболее заметен в случае разнолигандных комплексов толуилатов и циннаматов неодима(III). Так, при переходе от циннамата неодима(III) полимерного строения к разнолигандному соединению с 1,10-фенантролином уменьшение $E_{\text {св }}$ компонент спектра $\mathrm{Nd} 3 d$ свидетельствует об увеличении электронной плотности на ионе неодима(III).

Впервые проведена оценка энергии связи $\mathrm{Nd}(\mathrm{III})$ и в хинальдинатах неодима(III), имеющих различное строение (полимерное и островное). Поэтому для хинальдинатов неодима(III) наблюдаемую закономерность не рассматриваем.

Нами была сопоставлена относительная интенсивность перехода ${ }^{4} F_{3 / 2}-{ }^{4} I_{11 / 2}$ спектров люминесценции с зарядовым состоянием иона неодима(III) в синтезированных разнолигандных комплексных карбоксилатов с азот- и фосфорсодержащими нейтральными лигандами (табл. 2). В комплексных толуилатах и циннаматах неодима(III) с увеличением электронной плотности на атоме неодима(III) относительная интенсивность полос перехода ${ }^{4} F_{3 / 2}-{ }^{4} I_{11 / 2}$ в спектрах люминесценции возрастает.

Таким образом, изучены флуоресцентные свойства и электронное строение ряда новых комплексных карбоксилатов неодима(III). Показано, что с увеличением электронной плотности на атоме неодима(III) относительная интенсивность полос ${ }^{4} F_{3 / 2}-{ }^{4} I_{11 / 2}$-перехода в спектрах люминесценции комплексных соединений возрастает.

\section{Список литературы}

[1] Werts M.H.V., Woudenberg R.H., Emmerink P.G., Gassel R.V., Hofstraat J.W., Verhoeven J.W. // Angew. Chem. Int. Ed. 2000. V. 39. N 24. P. 4542.

[2] Smola S., Rusakova N., Korovin Yu. // J. Coord. Chem. 2011. V. 64. N 5. P. 863. 
[3] Мартынов А.Г., Сабонова Е.А., Горбунова Ю.Г., Цивадзе А.Ю. // ЖНХ. 2010. V. 55. № 3. Р. 389.

[4] Цвирко М.П., Мешкова С.Б., Венчиков В.Я., Большой Д.В. // Опт. и спектр. 1999. Т. 87. № 6. С. 950.

[5] Коровин Ю.В., Шевчук С.В., Бачериков В.А., Русакова Н.В., Алексеева А.А., Грень А.И. // Журн. неорг. химии. 2000. T. 45. № 9. C. 1513.

[6] Коровин Ю.В. // Укр. хим. журн. 2000. Т. 66. № 10. С. 101.

[7] Мешкова С.Б., Топилова З.М., Лозинский М.О., Русакова Н.В., Большой Д.В. // ЖАХ. 1997. Т. 52. № 9. С. 939.

[8] Mehta P.C., Tandon S.P. // J. Chem. Phys. 1970. V. 53. N 1. P. 414.

[9] Калиновская И.В., Мамаев А.Ю., Карасев В.Е. // ЖОХ. 2011. T. 81. № 8. С. 1242.

[10] Коровин Ю.В., Русакова Н.В., Жилина З.И., Водзинский С.В., Ииков Ю.В. // Укр. хим. журнал. 2002. Т. 69. № 6. C. 732.

[11] Мешкова С.Б., Кузьмин В.Е., Юданова И.В., Топилова З.М., Большой Д.В. // ЖНХ. 1999. Т. 44. № 10. С. 1671.

[12] Калиновская И.В., Мирочник А.Г., Карасев В.Е. // ЖНХ. 1991. Т. 36. № 7. С. 1778.

[13] Короченцев В.В., Шурыгин А.В., Вовна В.И., Калиновская И.В., Мирочник А.Г. // ЖСХ. 2017. Т. 58. № 6. С. 1165. doi 10.1134/S0022476617060087

[14] Короченщев В.В., Михайленко Е.В., Шурыгин А.В., Вовна В.И., Осьмушко И.С., Мирочник А.Г., Петроченкова Н.В. // Известия АН. 2017. № 11. С. 2081.

[15] Seah M.P. // Surf. Interface Anal. 1989. V. 14. P. 448.

[16] Небедов В.И. Рентгеноэлектронная спектроскопия химических соединений. // Справочник. М.: Химия, 1984. 256 с.

[17] Talik E., Kruczek M., Sakowska H., Ujma Z., Gala M., Neumann M. // J. Alloys Compd. 2004. V. 377 (1/2). P. 259.

[18] Cummins T.R., Egdell R.G. // Phys. Rev. B. 1993. V. 48. P. 6556.

[19] Szytula A., Penc B. // XVI National Symposium on Condensed Matter Physics. Sokobanja, 2004. P. 1.

[20] Radutoiu N., Teodorescu C.M. // Digest J. Nanomaterials and Biostructures. 2013. V. 8. N 4. P. 1535. 